\title{
A Study of Systemic Variation and Frequency of Modified Idioms In Forbes Asia and The Economist
}

\author{
LAILA PAYO (Corresponding author) \\ School of Languages, Literacies and Translation \\ Universiti Sains Malaysia, Malaysia \\ payo.laila@gmail.com \\ MANJET KAUR MEHAR SINGH \\ School of Languages, Literacies and Translation \\ Universiti Sains Malaysia, Malaysia \\ manjeet@usm.my
}

\begin{abstract}
Modified idioms or idioms with variation are figurative language that pose many semantic problems especially to non-native speakers of English. Apparently, a change in idiom form causes the message to be misunderstood by the non-native speakers as they lack familiarity of the modified idioms. Therefore, this case study aims to investigate the type and frequency of systemic variation of modified idioms found in Forbes Asia and The Economist. Glucksberg's (2001) textual analysis framework on modified idioms is applied as part of the qualitative analysis. The results of the study indicate that omitted, modified idioms with noun variation, and modified idioms with verb variation are types of systemic variation of modified idioms that are familiar to users. The findings of this study contributes toward identifying the type and frequency of modified idioms which affect familiarity and comprehension among readers of Forbes Asia and The Economist. Thus, the promotion of variation of modified idioms should focus more on types of variations with none or limited emergence of familiarity.

Keywords: idioms, modified idioms, omitted idioms, noun variation, systemic variation, verb variation
\end{abstract}

Published online: October 2020

To cite this article: Payo, L. \& Singh, M. K. M. (2020). A Study of Systemic Variation and Frequency of Modified Idioms In Forbes Asia and the Economist. International Journal of Language, Literacy and Translation 3(2), 46-60. https://doi.org/10.36777/ijollt2020.3.2.038

To link to this article: https://doi.org/10.36777/ijollt2020.3.2.038

This work is licensed under the terms of the Creative Commons Attribution (CC BY) (https://creativecommons.org/licenses/by/4.0/). 


\section{INTRODUCTION}

An idiomatic expression is a figurative language component that receives considerable attention due to its usage and occurrence. Idioms have gained attention among scholars, teachers, and language learners since the last two decades (Mantyla, 2004). Idioms are not always fixed on a certain expression as many researchers have proposed (Liu, 1998). Idioms allow change within context as language users wish to deliberately create an effect on the language. The variation of idioms mean the possibility to substitute words to the idiom form while still retaining meaning of the expression. Likewise, some idioms appeared with variations within their forms, except for invariant idioms or idioms that do not allow a single word to be changed, such as these idioms: give up or up to date (Liu, 2008). Many idioms show variation in use due reasons including creativity in language use. For example, 'a skeleton in the closet' to 'a skeleton in the cupboard', or 'a bad apple' to 'a rotten apple' (Liu, 2008, p.36). However, idioms that appear with variation or change within the context must represent the same figurative meaning of the intended idiom. Accordingly, the change in the original form of idiom produces a modified idiom (Omazi, 2008).

Modified idioms can be broadly divided into two types - systemic variation and creative variation idioms (Szczepaniak, 2006). Systemic variation can be sub-divided into three types including lexical, systematic and variations within frames (Liu, 2008). However, change in the original idiom structure produces modified idiom which causes misunderstanding to non-native English speakers in interpreting the meaning of the expression. The change in the original idiom forms influence the recognition skill of language users and affect the comprehension of idioms that lead to misunderstanding of messages (Omazi, 2008).

Consequently, modified idioms or idioms with variation pose many semantic problems especially to non-native speakers (Moon, 1998). It appears that many non-native English speakers often misunderstanding meaning of the message while reading context that contains modified idioms. Scholars such as McCarthy (2010) and Omazi (2008) indicated that variations from word change of an idiom produce a certain degree of confusion and lead to errors in understanding the intended message.

According to Moon (1998), many non-native speakers face difficulties in identifying accurate meaning of the modified idiom due to lack of familiarity. Non-native speakers are unfamiliar with the changes in idiomatic forms and therefore face difficulty in understanding messages (Moon, 1998). Familiarity, influenced by frequency of occurrence impacts the comprehension of idioms. The more frequent modified idioms occur, the familiar language users are to modified idioms in a language. This proves that higher frequency of modified idiom occurrence increases familiarity of readers with modified idioms (Sameer, 2013). The frequency of modified idioms in language will indicate level of familiarity and comprehension among language users, exploring the frequency of modified idioms is significant to understand the familiarity. Therefore, an investigation on frequency of modified idioms appearing in a context could determine familiarity with modified idioms among language users'.

However, idiom variants can be modified in terms of lexical variation and grammatical structure, called systemic variation which includes lexical variation, systematic variation, and 
variation within frames (Moon, 1998). The exposure of modified idioms according to their systemic variation will provide an insight into the users' level of idiomatic familiarity.

Furthermore, investigating systemic variation types of modified idioms in journalism context has not been reported in the literature. No collection of modified idioms has been recorded as previous research focused on the purpose of pedagogy (Anwar, Tahir \& Qureshi, 2018). Such an investigation will indeed provide insight in understanding the use of modified idioms and study frequency of modified idioms will indicate a degree of familiarity. Thus, this study aims to explore the types of systemic variation of modified idioms in the economic journalism context of Forbes Asia and The Economist.

Therefore, objectives of this study are

1. To categorise modified idioms published in Forbes Asia into lexicon variation, systematic variation, variation within frames.

2. To identify the frequency of modified idioms used in Forbes Asia magazine according to types of systemic variation.

3. To categorise modified idioms published in The Economist into lexicon variation, systematic variation, variation within frames.

4. To identify the frequency of modified idioms used in The Economist according to types of systemic variation.

5. To compare the different types of systemic variation of modified idioms found in Forbes Asia and The Economist.

\section{LITERATURE REVIEW}

\section{COMPREHENSION OF MODIFIED IDIOM}

The interpretation of modified idiom is challenging whereby meaning of modified idioms cannot be derived from the meaning of their constituent words. Consequently, the comprehension of modified idiom can be achieved when the variant lexis of the idiom can be recognised as it belongs to a particular lexical set (Moon, 1998). Therefore, modified idiom are part of figurative language that requires identifying and comparing the variant idiom with the original in the process of comprehension. Process of identifying variances of modified idiom will reveal the original form and assist in understanding the accurate meaning of modified idioms (Omazi, 2008).

The interpretation process of modified idiom comprises strategy used in revealing original form of the idiom. It includes process of interpreting and identifying the variances of idiom. This process assists the understanding of modified idiom which appears with a change within contexts. Therefore, interpretation process of modified idiom requires a reliable tool to identify and compare the variances of modified idiom. The use of specialised phraseological dictionaries or idiom dictionaries is recommended to interpret the meaning of modified idiom (Omazi, 2008). 


\section{MODIFIED IDIOM AND ITS SYSTEMIC VARIATION}

Modified idiom is a term that refers to an idiomatic expression which presents the variation within the form (Omazi, 2008). Variation of an idiom is process of changing different lexis to the original form of idiom while maintaining idiomatic meaning of the expression. The substitution can be in terms of synonyms or antonyms (Moon, 1998). For example, the idiom 'hide your head in the sand' was changed to 'lift your head in the sand', where the verb 'hide' is replaced with 'lift' which are opposite in meaning but maintains the meaning of the expression idiomatically (Vrbinc \& Vrbinc, 2011, p. 80). Moreover, idiomatic change could also occur by shortening or expending the expression from its original form. For example, the idiom 'a bird in hand is worth two in the bush' can be omitted to only 'a bird in hand' (Liu, 2008, p.37)

Systemic variation is the process of modifying or changing idiom context within the constraints of lexicological or phraseological system of the idiom (Glaser, 1986). Systemic variation displays regularity and affects meaning of the expressions. It involves both lexical and syntactical changes by reflecting deeply on the grammatical systems and relationships (Liu, 2008).

Langlotz (2006) indicated that systemic variation displays regularity reflecting the concepts of the variant and the original context of an idiom. It often uses the simple syntactic form of context. According to a study by Moon (1998), there are three types of systemic variationlexical variation, systematic variation, and variation within the frames.

\section{(1) Lexical Variation}

Lexical variation refers to lexis variant of the idiomatic form. It is substitution of one or more common words in the idiomatic form. Lexical variation is created from words that can be replaced and it is compatible with the relationship between the substituent and the idiomatic expression (Langlotz, 2006). The table below shows the types of lexical variation (Liu, 2008, p. 36).

Table 1

Types of Lexical Variation

\begin{tabular}{|c|c|}
\hline Types of lexical variation & nple \\
\hline Verb variation & $\begin{array}{l}\text { he ball rolling' or 'start the ball rolling', } \\
\text { he ante' or 'raise the ante' }\end{array}$ \\
\hline Noun variation & $\begin{array}{l}\text { eton in the closet' or 'skeleton in the cupboard, } \\
\text { ull before the storm' or 'the calm before the storm' }\end{array}$ \\
\hline Adjective or modifier variation & d apple' or 'a rotten apple' \\
\hline Particle variation & ıll throttle' or 'at full throttle' \\
\hline
\end{tabular}




\section{(1) Systematic Variation}

Systemic variation is idiomatic variation produced by changing the grammatical structure of expression (Liu, 2008). Systematic variation weakens fixed expression of an idiom and alters grammatical form of the original idiom. For example, 'To coin a phrase, Lewis's war-time broadcasts on behalf of God put a pigeon among the cats'; derived from idiom: put the cat among the pigeons (Langlotz, 2006, p. 197).

Systematic variation can be divided into different changes that includes modification with expansion, modification with shortening, grammatical modification, coordination, and combination of different types of variation (Vrbinc \& Vrbinc, 2011).

\section{- Expansion}

Idiom can be modified through the expansion of its expression by adding adjectives, adverbs, or prepositional phrases to the base form of the idiom in an attempt to add information to the context. For example '... Alistair Mackintosh, Manchester City's chief (presumably still grateful that Sport England footed a $£ 165 \mathrm{~m}$ bill for the 2002 Commonwealth Games, including the very stadium which Man City now plays in' (Private Eye magazine, 17/02-02/03/06; p. 8). It can be seen that modified idiom is formed through expansion of the base form of 'foot the bill (for something)' (Vrbinc \& Vrbinc, 2011, p. 81).

- $\quad$ Shortening

Systematic variation of shortening is modification that omits part of idiom from the original idiomatic form. For example, 'a bird in hand is worth two in the bush' can be omitted to only ' $a$ bird in hand' (Liu, 2008, p.37). However, not all truncated idioms are modified with systematic variation. If the context does not support the idiomatic meaning of the expression and the meaning cannot be interpreted correctly, it is not possible to omit the expression (Liu, 2008).

- Grammatical Modification 
According to a study by Vrbinc and Vrbinc (2011), there are four different types of grammatical modification that modifies an idiom.

Table 2

Types of Grammatical Modification of Systemic Variation among Modified Idioms

\begin{tabular}{llllll}
\hline Type of grammatical modification & Example of a modified idiom & \multicolumn{2}{l}{ Original idiom } & \\
\hline $\begin{array}{l}\text { Original verbal idioms have been } \\
\text { replaced by nominal modification. }\end{array}$ & $\begin{array}{l}\text { 'Yet again Greenberg moved in with a } \\
\text { hand-washing briefing: ... (Private Eye } \\
\text { magazine, 14/04-27/04/06; p. 11)' }\end{array}$ & & (somebody/something) & hands & of \\
& & & & \\
\hline
\end{tabular}

Change of the degree of comparison. The woman with the face transplant was in the papers today. I thought she would

keep a low profile

keep a lower profile (Private Eye

magazine, 14/04-27/04/06; p. 14)'

A noun in the context of the idiom may undergo change in number
He could have avoided much costly admin by copying the Welsh scheme in the first place but then he wouldn't have had two bites of the cherry.' (Private Eye magazine: 31/03-13/04/06; p. 26) a bite of the cherry

'scrape (the bottom of the barrel' Lord Levy calling for state funding of political parties is the sound of the bottom of the barrel being scraped (Private Eye magazine: 17/03-30/03/06;

p. 3),

\section{- Coordination}

This type of systematic change refers to the combination of two or more idioms or two types of variations. Modification with coordination is done whereby one idiom will retain its base-form and the other one is found in an elliptical form. For example, 'It's a miracle. I am over the hill ... I mean the moon. (Private Eye magazine: 12/05-25/05/06; p. 19); modification done by combining two idioms 'over the hill' and 'be over the moon', while the idiom 'be over the moon' is used in the omitted form (Vrbinc \& Vrbinc, 2011, p. 85).

\section{(1) Variation Within Frames}

Variation within frames is the change of nouns that occur within a fixed frame of an idiom. The meaning of the variant expression is often identical or similar. For example, 'down the drain,' 'down the pan,' 'down the toilet,' 'down the tube' (Liu, 2008, p. 37). In many cases, the variation within frame shows no connection in terms of meaning but still bound to the set of lexical form in context of the idiom (Liu, 2008). 


\section{FAMILIARITY OF MODIFIED IDIOMS}

Familiarity is an important feature in the process of idiom comprehension has been widely used to describe the characteristics of idioms (Liu, 2008). It directly influences the difficulty that a learner may encounter in comprehending idioms. Familiarity defines how frequent an individual faces idiom while using language. For example, 'have a soft spot' is an idiom which appears quite often and it is understood by many non-native speakers due to its high frequency in language use (Sameer, 2013).

Apparently, understanding figurative use of language depends on the amount of exposure one has to non-literal expressions (Mantyla,2004). Idiom which occurs often will be easily understood than a less common idiom. The high familiarity of idioms like 'keep up one's end' and 'skating on thin ice' make idioms easier to understand than moderate or low familiar expressions such as 'vote with one's feet' and 'take down a peg' (Nippold \& Rudzinski, 1993).

According to previous studies, researchers have agreed that accuracy of idiomatic comprehension increases during late childhood and improves in adulthood. The ability to interpret the meaning of idiom is closely related to idiom familiarity (Sameer, 2013). Sameer (2013) examined the amount of time a person requires to process both familiar and unfamiliar idioms by placing the subjects into two different contexts which included idioms in figurative and literal contexts. The first context involved sense of figurative interpretation, and another context was based on a literal understanding. The recorded time of the responses showed that respondents read familiar idioms much faster than unfamiliar idioms both in figurative and literal contexts. Therefore, the study concluded that comprehending unfamiliar idioms is more challenging (Sameer, 2013).

Moreover, variations of idiom have made comprehension of idioms challenging as the variant form of idioms are not common to many non-native speakers (Nippold \& Rudzinski, 1993; Moon, 1998). Thus, the familiarity with idioms or the original form of idioms will affect the comprehension of the modified idiom (Mantyla, 2004).

\section{CONCEPTUAL FRAMEWORK}

This study was designed to investigate the frequency of modified idioms in order to determine the familiarity among non-native language users. The understanding of idiomatic comprehension and its types are needed to conduct this analysis. Thus, the framework of this analysis include comprehension of idioms and modified idioms, and modified idioms with variations.

Idiomatic comprehension is the process of understanding idioms including identification of modified idioms into a particular lexical set. Theories related to modified idioms and idiom variations proposed by Langlotz (2006), Moon (1998), Liu, (2008) and Vrbinc and Vrbinc (2011) have provided the understanding of different types of variations that are available to idiom variant. 


\section{METHODOLOGY}

Qualitative research is implemented to provide an understanding frequency of modified idioms and the familiarity. Textual analysis of modified idioms types that appeared in the context of a Forbes Asia and The Economist are the main focus of this study. Likewise, this study designs to follow the process of modified idiom comprehension proposed by Glucksberg (2001). It is a model of textual analysis which includes process of identifying and verifying the modified idioms. Glucksberg's (2001) textual analysis combines both processes identification of modified idioms and verification of its form. The identification process of modified idioms comprises an understanding of the idiomatic structure to recognise the idiom and its variant in the context. The verification process refers to connection between the original idiom and its modification (Glucksberg, 2001)

\section{SAMPLING METHOD AND SAMPLE SIZE}

This study applies purposive sampling as it helps the researcher focus on characteristics of text collection and enables the researcher to answer research questions. In regards to the sample size, this research covers 100 modified idioms from 10 issues of two business magazines, comprising 50 modified idioms from Forbes Asia and 50 modified idioms from The Economist.

\section{RESEARCH PROCEDURES}

The analysis of modified idioms follows Glucksberg's (2001) textual analysis framework. Thus, the research procedure comprises four phases:

Phase 1: Identification of modified idioms. This process deals with the recognition of figurative sense to identify modified idioms in the context. Identification of idiom refers to recognition process of idiomatic string from the idiom context, as the idiom string makes the expression recognised (Cacciari \& Tobossi, 2014). Any idiom with variation is considered a modified idiom and will be counted in the corpus result set.

Phase 2: Variant verification. This process deals with verification of modified idioms found in the context. The corpus result set (modified idiom) compiled during Phase 1 goes through the verification process of the original idioms. It is a comparison process between the idiom form in the corpus result set and idiom in dictionary (McGraw-Hill's American Idioms Dictionary). This process designs to affirm the difference in form from the original idioms found in the idiom dictionary.

Phase 3: Data categorisation. Verified corpus set is categorised according to the types of variations. The categorisation of modified idioms is illustrated to assist the study with interpretation of modified idioms and frequency of its occurrences.

Phase 4: Frequency and usage analysis. This process analyse the systemic variation frequency of modified idioms by comparing context of Forbes Asia and The Economist. The outcome of the discussion is drawn at the end of the study. 


\section{A CASE STUDY OF FORBES ASIA AND THE ECONOMIST}

In exploring the use of modified idioms, idioms with variation is found to be a common language use, frequently found on the headlines of news or content in articles. It is a figurative speech engaged to produce stylistic and memorable language to the context (Glaser, 1986).

Forbes Asia and The Economist are business magazines that were selected because numerous studies of the journalistic contexts are focused on reviewing and identifying media context (Perrin, 2013). Thus, a gap on linguistic study of journalistic context is discovered in research. Forbes Asia and The Economist are chosen for the following reasons:

(1) Language in Forbes Asia and The Economist magazine contains a large number of figurative speech, including idioms (Glaser, 1986). Thus, the context in Forbes Asia and The Economist incorporate modified idioms.

(2) The articles in Forbes Asia and The Economist apply different writing styles. The Economist comprises expository style while Forbes Asia has descriptive writing. Thus, exploring the context of Forbes Asia and The Economist could be productive as the data contains larger database of journalistic language. Business magazines are interested not only on enterpreneurs but also regular readers who follows the business world. Understanding modified idioms can help readers accurately interpret news and trends of the business world. Forbes Asia and The Economist are two famous business magazines (Columbres, 2016), hence, can be assumed that the journalistic language used is desired by readers.

\section{RESULTS}

Results from the analysis presented according to the context of the case study, which are Forbes Asia and The Economist.

\section{RESULTS FROM FORBES ASIA}

The results from Forbes Asia reveal lexical variation, systematic variation, and variation within frames are among the types of systemic variation appeared in the corpus. Noun variation, verb variation, adjective variation, are types of lexical variation of systemic variation found in the context. Modification with shortening, modification with expanding, grammatical modification and modification with coordination are types of systematic variation found. The frequency of each modification is shown in Table 3 below.

Table 3

The Frequency of Types of Modified Idioms in Forbes Asia 


\begin{tabular}{cccc}
\hline & Types of Modified Idioms & $\begin{array}{c}\text { Total frequency } \\
\text { (idiom) }\end{array}$ & $\begin{array}{c}\text { Total frequency } \\
\text { (idiom) }\end{array}$ \\
\hline Lexical variation & Noun variation & 13 & 24 \\
& Verb variation & 10 & \\
& Adjective variation & 1 & 23 \\
\hline Systematic variation & Shortening & 16 & \\
& Expansion & 3 & 3 \\
\hline Variation within frames & Ctical modification & 3 & 1 \\
\hline
\end{tabular}

\section{RESULTS FROM THE ECONOMIST}

Noun variation, verb variation, adjective variation, are types of lexical variation of systemic variation found in The Economist. Modification with shortening, modification with expanding, grammatical modification and modification with coordination are types of systematic variation found in the context. The frequency of each variation is shown in Table 4 below.

Table 4

The Frequency of Types of Modified Idioms in The Economist

\begin{tabular}{llcc}
\hline \multicolumn{2}{c}{ Types of Modified Idioms } & Total frequency & $\begin{array}{c}\text { Total } \\
\text { frequency } \\
\text { (Idiom) }\end{array}$ \\
\hline Lexical variation & Noun variation & 12 & 28 \\
& Verb variation & 12 & 19 \\
& Adjective variation & 4 & \\
\hline Systematic variation & Shortening & 8 & 3 \\
& Expansion & 6 & 2 \\
\hline
\end{tabular}

Furthermore, the analysis show that there are no difference in the type of modified idioms used both in Forbes Asia and The Economist magazines. The context of Forbes Asia and The Economist are presented by lexical variation, systematic variation, and variation within frames. Noun variation and verb variation of lexical variation are types of variation commonly found in 
The Economist and Forbes Asia. The difference between modification of idioms is presented below.

Table 5

The Difference between Modified Idioms in Forbes Asia and The Economist

\begin{tabular}{llcc}
\hline \multicolumn{1}{c}{ Types of Modified Idiom } & $\begin{array}{c}\text { Frequency of Modified } \\
\text { Idiom in Forbes Asia } \\
\text { (Expression) }\end{array}$ & $\begin{array}{c}\text { Frequency of Modified } \\
\text { Idiom in The Economist } \\
\text { (Expression) }\end{array}$ \\
\hline Lexical variation & Noun variation & 13 & 12 \\
& Verb variation & 10 & 12 \\
& Adjective variation & 1 & 4 \\
\hline Systematic variation & (Total lexical variation) & 24 & 28 \\
& Shortening & 16 & 8 \\
& Expansion & 3 & 6 \\
& Grammatical modification & 3 & 2 \\
& Coordination & 1 & 19 \\
\hline Variation within frames & (Total systematic variation) & 23 & 3 \\
\hline
\end{tabular}

A noticeable difference of modification with shortening could be seen between Forbes Asia and The Economist. Modification with shortening is used quite frequently in Forbes Asia if compared to The Economist. Furthermore, it appears that adjective variation from lexical variance is rarely used in the context of Forbes Asia. The type of modification which is used less in The Economist is grammatical modification.

\section{DISCUSSION}

\section{TYPES AND FREQUENCY OF MODIFIED IDIOMS IN FORBES ASIA}

Results show appearance of three systemic variations in Forbes Asia, these include lexical variation, systematic variation, and variation within frames. The results also reveal that all idioms in the corpus are modified with lexical variation and systematic variation. Non-native readers of Forbes Asia can easily understand lexical variation and systematic variation of modified idioms. Modified idioms with omission in forms are easy to interpret due to the frequency of the appearance in the expository language of Forbes Asia. Thus, familiarity that occurs based on the frequency of omitted idioms in expository language has made it easier to perceive expressions.

This study has also shown that adjective variation and modification with coordination of modified idioms are types of idiom variation that may cause difficulty for readers of Forbes Asia 
due to its low frequency of occurrence. Furthermore, variations that did not appear in Forbes Asia like particle variation, conjunction variation, and modification between English varieties are considered difficulty by most readers of expository language.

As stated by Sameer (2013) and Moon (1998) who focused on relationship between frequency and comprehension, frequent highlighting of a modified idiom creates familiarity among users or readers. Since are no expressions with particle variation, conjunction variation, and variable between English varieties in Forbes Asia, the study has concluded that readers of expository language will face difficulty in interpreting the accurate meaning of the expressions. However, with reference to the types of lexical variations that were reported by Moon (1998), Langlotz (2006), Liu (2008), Vrbinc and Vrbinc (2011), some of these variations were not detected in the analysis of corpus that was extracted from Forbes Asia.

Those variations are particle variation, conjunction variation, and variation between English variety. Taking this into account, it can be concluded that modified idioms with noun variation, verb variation, adjective variation, modification with shortening, modification with expansion, grammatical modification, modification with coordination and variation within frame are familiar to language users who read Forbes Asia magazine.

The promotion of modified idioms should also focus on types of variations with no emergence of familiarities, such as adjective variation, modification with coordination, particle variation, conjunction variation, and variation between English varieties.

\section{TYPES AND FREQUENCY OF MODIFIED IDIOMS IN THE ECONOMIST}

Lexical variation, systematic variation, and variation within frames are the three types of modification that occurred in The Economist. The results show that readers of The Economist are more familiar with modification of noun variation and verb variation compared to lexical variation. This corresponds to Mantyla's (2004) study stated that familiarity is considered a factor that influences comprehension of idioms and familiar idiom are interpreted faster than. Thus, the understanding of noun variation and verb variation is believed to be achieved through language users' familiarity with the expressions.

Moreover, findings indicate that grammatical modification from systematic variation is the type of modification that is unfamiliar to readers of descriptive language. The occurrence of modified idioms with grammatical modification is low. Herrmann (2008) stated the least expressions appear in a language the challenging it is interpreting the expressions. The impact of expressions recognition in reader's memory is influenced by the frequency of its appearance.

For these reasons, the study encourages promotion of modified idioms to readers of the descriptive language. The infrequent variations of modified idiom should be promoted in order to provide an understanding of idioms among readers of descriptive language. This will also give an insight on expressions and reduce error in understanding messages that contain modified idioms.

THE DIFFERENCES IN THE RESULTS OF THE CASE STUDY 
The study has shown no difference in types of modified idioms found in Forbes Asia and The Economist as both magazines use lexical variation in the language contrasting with variation within frames.

It can be concluded that readers of the expository language found in Forbes Asia and descriptive language of The Economist are familiar with lexical variation and systematic variation of modified idioms than idioms with variation within a frame. However, it seems that readers of descriptive language are more familiar with lexical variation as it has notable domination among other types of modified idioms, while readers of expository language are equally familiar with both lexical variation and systematic variation.

However, there are differences in terms of familiarity shown by readers of expository language and descriptive language. Readers of expository language are familiar with omitted idioms while readers of descriptive language have more familiarity with noun variation and verb variation of modified idioms. Furthermore, as previous study on frequency and language acquisition proposed by Rizq (2015) stated that frequency of input influences language acquisition. Modified idioms with particle variation, conjunction variation and variation between English are considered as types of modified idiom with less contribution to user's memories and the ability of acquiring its comprehension.

\section{RECOMMENDATION}

The present study has proven that figurative expression of modified idioms have caused difficulty among non-native readers in comprehending the intended meaning of the context. In the spite of that, this study has provided an understanding of how modified idiom was understood through the study of frequency of its occurrence in regards to journalistic language.

The study recommends further research on types of modified idioms aside from omitted idioms noun variation as familiarity of these variations have already been generated. The awareness of variations of modified idioms should focus more on modified idioms with grammatical modification, modified idioms with adjective variation, and modified idiom with coordination. Moreover, modified idioms with particle variation, conjunction variation, or variation between English varieties are highly encouraged to use increasing an understanding of the unfamiliar expressions.

Accordingly, this study would like to suggest an in-depth examination on several reading materials which may contain modified idioms such examining modified idioms in novels or in academic writing. Moreover, taking into account the important role of familiarity, a future study may focus on other factors that also affect the comprehension of modified idioms.

\section{LIMITATION}

This study has been designed to only focus on one particular filed, which is business journalism and has not included other types of magazines. Secondly, the study is limited to variations of systematic modified idiom. 


\section{CONCLUSION}

In conclusion, comprehension of modified idioms is affected by the frequency of occurrence in English language. This study has revealed the importance of understanding expressions through the familiarity of modified idioms in journalism. The increase in occurrence of an expression results in an increase in its familiarity, leading to the possibility of its comprehension by nonnative readers. Categorisation and discussions were expected to be useful for better understanding of modified idioms making it a significant contribution of this study. The outcome of this study hopes to raise awareness on the state of modified idioms in context and a possible promotion on the different types of modified idiom to non-native language users. In summary, this study provides a better understanding on familiarity of modified idioms among non-native speakers of English in business journalism.

\section{REFERENCES}

Anwar, B., Tahir, A. \& Qureshi, A. H. (2018). Pedagogy of English Idioms: An Etymological Perspective. International Journal of English Linguistics, 8, 210-275. https://doi.org/10.5539/ijel.v8n3p270

Cacciari, C. \& Tabossi, P. (2014). Idioms: Processing, Structure, and Interpretation. New York: Psychology Press. https://doi.org/10.4324/9781315807133

Glaser, R. (1986). Linguistic Theory and Historical Linguistics (Trends in Linguistics: Studies and Monographs). Amsterdam: Mouton de Gruyter.

Glucksberg, S. (2001). Understanding figurative language: From metaphors to idioms. New York: Oxford University Press. https://doi.org/10.1093/acprof:oso/9780195111095.001.0001

Herrmann, B. (2008). Idiom Comprehension in Bilingual and Monolingual Adolescents. Graduate Theses and Dissertations. Univeristy of South Florida. Retrived from Http://Scholarcommons.Usf.Edu/Etd/256

Langlotz, A. (2006). Idiomatic Creativity A cognitive-linguistic model of idiom-representation and idiom-variation in English. Philadelphia: John Benjamins Publishing Company. https://doi.org/10.1075/hcp.17

Liu, D. (2008). Idioms: Description, comprehension, acquisition, and pedagogy. New York: Routledge.

Mantyla, K. (2004). Idioms and language users. Retrieved from https://www.researchgate.net/publication/277872357.

McCarthy, M. (2010). English idioms in use. New York: Advanced Cambridge University Press.

Moon, R. (1998). Fixed expressions and idioms in English: a corpus based approach. Oxford: Clarendon Press. 
Omazi, M. (2008). Processing of idioms and idiom modifications: A view from cognitive $\begin{array}{llll}\text { linguistics. } \quad \text { Phraseology: An Interdisciplinary Perspective, } & \text { 67-79. }\end{array}$ https://doi.org/10.1075/z.139.09oma

Rizq W (2015). Teaching English Idioms to L2 Learners: ESL Teachers' Perspective. St. Cloud State University.

Sameer, S. A. (2013). 'EFL Students' Judgments of English Idiom Familiarity and Transparency'. Journal of Language Teaching and Research, 4, 662-669. https://doi.org/10.4304/jitr.4.4.662-669

Spears, R. (2006) McGraw-Hill's Dictionary of American Idioms Dictionary. Chicago: NTC Pub.

Szczepaniak, R. (2006). The Role of Dictionary Use in the Comprehension of Idiom Variant. Germany: Max Niemeyer Verlag. https://doi.org/10.1515/9783110891713

Vrbinc, A. \& Vrbinc, M. (2011). Creative Use of Idiom In Satirical Magazines. Retrieved from: hrcak.srce.hr/file/107984. 